\title{
A EQUIPE DE SAÚDE E A LAVAGEM DAS MÃOS NO CONTROLE DAS INFECÇÕES HOSPITALARES
}

\author{
Rita de Cássia Nogueira Barros* \\ Rosiléa Alyes Nogueira*
}

\begin{abstract}
RESUMO - As autoras realizaram estudo sobre a lavagem das mãos entre os componentes da equipe de saúde, buscando identificá-la como um meio de redução da incidência de infecções hospitalares. O estudo foi desenvolvido no perlodo de agosto a novembro de 1988, na Maternidade Escola Assis Chateaubriand e é constituldo de uma população amostral de oito enfermeiros, vinte e quatro médicos e vinte e três ocupacionais de enfermagem. Os resultados obtidos demonstram a pouca importância dada a esta prática e evidenciam a necessidade de um programa educativo sistemático sobre este assunto.
\end{abstract}

ABSTRACT - The authors realized the research about the hands wash between the healt workers. This study, which included eight nurses, twenty four medics, and twenty three auxiliary nurses, were realized from August through November of 1988 at the Assis Chateaubriand Teaching Maternity Hospital (MEAC), an important element in the Ceará Federal University Medical Complex. The results obtained demonstrate the need of periodics meetings about this subject.

\section{INTRODUÇÃO}

O controle das infecções hospitalares $e$ hoje um dos objetivos da Saúde Pública do Brasil, devendo-se a este fato um alto índice de morte por infecção hospitalar: em média de 300.000 casos e 41.000 6́bitos por infecção hospitalar por ano, e ainda calcula-se que $6,5 \%$ dos pacientes internados em hospitais contraem infecção hospitalar ${ }^{3}$.

A infecção cruzada é considerada uma das principais causas das infecções hospitalares, cuja transmissão se faz também através das mãos dos funcionários e profissionais da área de saúde ${ }^{3}$.

A lavagem das mãos como prevenção das infecções hospitalares, reduz consideravelmente os casos das mesmas. Apesar de ser uma prática comprovadamente eficaz desde 1847 com Semmelweis, (1, 3, 6, $18,19)$ tem sido colocada em segundo, ou até mesmo, em último plano. Geralmente, argumentos como: "falta torneira adequada", são usados para justificar o descaso dos funcionários e profissionais de saúde para com esta técnica.

E sempre se escudando em justificativas enganosas, os funcionários e profissionais de saúde passam por várias atividades sem lavar as mãos ou lavando-as de maneira incorreta.

Somando-se a esta problemática, encontramos também os ornamentos pessoais, que apesar de realçar a estética, repercutem também na disseminação de microrganismos não eliminados durante a lavagem das mãos.

Considerando a importância da lavagem das mãos, é natural que se faça os seguintes questionamentos:

1) A lavagem das mãos tem sido realizada corretamente?

* Enfermeiras da Matemidade Escola Assis Chateaubriand - CE

2) A equipe de saúde valoriza esta prática como meio de reduzir a infecção hospitalar?

3) Como o enfermeiro pode divulgar a importância da prática da lavagem das mãos?

\section{OBJETIVOS}

\section{Objetivo Geral}

Identificar a lavagem das mãos como meio de redução das infecções hospitalares, propondo estratégias que estimulem esta prática.

\section{Objetivos Específicos}

1. Avaliar a prática da lavagem das mãos em ocupacionais de enfermagem e profissionais de saúde, relacionando-as com a infecção hospitalar.

2. Relacionar a microflora das mãos com a prática em questão, propondo estratégias que estimulem a conduta da lavagem das mãos.

3. Divulgar a partir dos resultados obtidos, a importância desta prática.

\section{REVISÃO DE LITERATURA}

O controle das infecções hospitalares não ê uma atividade hospitalar recente. Vários autores ${ }^{6}, 22$ ressaltam o papel de James Young Simpson, professor de cirurgia da Universidade de Edimburg, no controle das infecções hospitalares, quando na primeira metade do século passado realizou um estudo comparativo entre a mortalidade por supuração em 2.000 pacientes "amputados em hospitais", com a de igual número de 
pacientes "amputados em casa", tendo como resultado um maior índice de mortalidade em pacientes hospitalizados, introduzindo então ò termo HOSPITALIS$\mathrm{MO}$, para referir-se aos riscos inerentes à assistência hospitalar.

Segundo ZANON"2 "Oliver Wendel Holmes, em 1843, sugeriu que os médicos, inconscientemente, eram a causa maior das complicações infecciosas da parturiente e do recém-nascido". Essa hipótese teria confirmação epidemiologica cinco anos depois, com os estudos de Ignaz Phillip Semmelweis ${ }^{1}, 3,6,18,10$, ao preocupar-se e estudar o alto índice de mortalidade nas enfermarias obstétricas assistidas por estudantes de Medicina, comparando com a mortalidade de enfermarias assistidas por parteiras; chegando a conclusão de que os estudantes, apరs passarem pela sala de necropsia, assistiam às parturientes, sem lavar as mãos, tendo portanto as mãos como veículo de transmissão da febre puerperal. Semmelweis lutou com suas armas para controlar as infecções hospitalares, não importando-se de ser chamado "Maníaco de Limpeza", porém teve um trágico final. "vagando loucamente pelas ruas, chamando os médicos e hospitais de assassinos premeditados ${ }^{19}$ ".

Importa destacarhos a contribuição dada por PASTEUR $^{19}$ em 1861 e LISTER ${ }^{19}$, em 1867. O primeiro destacando que a fermentação era causada por micróbios vivos, e o segundo apresentado os princípios de assepsia e antissepsia hospitalar.

Nessa época, poucos profissionais acreditavam na ocorrência das infecções hospitalares. Este fato está bem claro na resposta dada por Lister, em 1987, ao editorial da revista The Lancet, o qual criticava sua teoria de germes vivos, dizendo: "Esforçai-vos por ver com os olhos do espírito os germes vivos que podem infeccionar um ferimento, justamente como verdes as moscas com os olhos do corpo ${ }^{19 "}$.

Diante do exposto, vale salientar a contribuição dada por Kock, em 1881, ao apresentar seus postulados comprovando etiologicamente as infecções, "dando olhos aos espíritos mais discrentes ${ }^{6}$ ".

Desde essa época até os dias de hoje, muitos caminhos foram trilhados, porém, apesar das diversas tentativas de controlar as infecções hospitalares, estas ainda estão cobrando um elevado tributo em morbimortalidade e de custos hospitalares.

É interessante registrar a citação de FERRAZ ${ }^{8}$ : "Âo ser admitido no hospital, o paciente, doente ou portador de um condição predisponente, apresentando uma diminuição de sua capacidade de defesa, é submetido a procedimentos invasivos, com o objetivo de tratar ou esclarecer sua doença. Em contato com uma população bacteriana altamente agressiva, selecionada ao longo dos anos no hospital, por sua competência e resistência, esse paciente complica ou adquire duença, em última análise, infecção, dentro do ambiente do hospital".

Os riscos de contrair estas enfermidades nosocomiais são inúmeros e vale ressaltar seus mecanismos de transmissão.

Para que ocorra uma infecção, faz-se necessário o contato ou penetração do microorganismo nos tecidos do hospedeiro. O contato ocorre através de uma interação química entre verdadeiros sítios ativos que existem nas membranas do hospedeiro e do microrganismo. Assim sendo, podemos dizer que está explicada a seletividade que as bactérias apresentam em relação às espécies e aos tecidos dos hospedeiro ${ }^{16}, 20$.

A pele e mucosas dos seres humanos são normalmente habitadas por um grande número de bactérias, que ao mesmo tempo em que se apresentam como eficiente meio de defesa, são também os principais causadores das infecções hospitalares. Estas infecções ocorrem quando há fatores que desequilibram a estabilidade em que vivem os germes e hospedeiros ${ }^{16,20}$ 21.

FRACATORIUS, em 1546, citado por FERNANDES", afirmava que "distinguimos três tipos de contágio: por contato direto, por fômites como objetos de madeira ou vestuário, e pelo ar, que ê o mecanismo menos frequente".

Dessa forma as infecções hospitalares podem ser subdivididas em:

a) Infecção Endógena (auto-infecção) - causada por microrganismos da flora normal do paciente;

b) Infecção Cruzada - adquirida por contato direto, a partir de outros pacientes e profissionais de saúde;

c) Infecção Ambiental - quando o microrganismo é proveniente de objetos ou de fontes ambientais ${ }^{10}$.

No que se refere às vias de transmissão das infecções hospitalares, a de maior relevância é a cruzada, tendo o homem como o seu reservatorio, vetor e receptor ${ }^{5}$.

Em virtude de ser a lavagem das mãos o objeto do presente trabalho, nos deteremos no estudo desta prática.

Para melhor compreendermos a técnica da lavagem das mãos, necessário se faz um breve relato sobre a microbiologia das mãos.

"A pele ou cútis é o manto de revestimento do organismo, indispensável à vida, já que isola componentes orgânicos do meio exterior, impede a ação de agentes externos de qualquer natureza, evita perda de água, eletrólitos e outras substâncias do meio interno, dá proteção imunologica, faz termorregulação, propicia a percepção e tem função secret ria $^{3}$ ".

Numa análise microbiologica a pele apresenta-se com duas populações: a flora residente e a flora transitoria.

A flora residente é composta por microrganismos que vivem e se multiplicam na pele. São relativamente estáveis em número e tipo; são mais encontradas nas dobras, nas rachaduras da pele em torno e sob as unhas. No que se refere a remoção desta flora, encontra-se uma certa resistência à lavagem com água e sabạ̃o, a menos que uma fricção considerável também seja feita com uma escova, entretanto é inaltivada por anti-sépticos $3,10,11$.

A flora residente tem baixa virulência e raramente causa infecção, podendo contudo ocorrer infecções sistêmicas em pacientes imunodeprimidos e apos procedimentos invasivos ${ }^{3}$.

Por outro lado, não se considera poșsível limpar a pele de todas as bactérias.

A flora residente é representada por "difteroides aeróbios e anaeróbios (por exemplo Corynebacterium, Propionibacterium); estafilococus não hemolíticos, aeróbios e anerobios (S. epidermidis, Preptococus); bacilos gram-positivos, aeróbios e esporulados, encontrados no ar, água e solo, estreptococus alfa-hemolíticos (S. viridians) e enterococus (S. faecalis); bacilos gram-negativos, coliformes e acinetobacter (He- 
rellea). Fungos e leveduras estão comumente presentes nas dobras da pele ${ }^{14 "}$.

A flora transitória é uma flora passageira, composta por microrganismos patogênicos e não patogênios depositados sobre a pele, os quais se mantêm viáveis por período inferior a 24 horas. São encontrados na superfície da pele, junto à gordura, lipídios e sujidades, por esse motivo são facilmente removíveis pela lavagem com água e sabão ou detergente, pelo uso de anti-sépticos ou por ambos ${ }^{3}{ }_{2}^{10,11}$.

"A flora transitória das mãos de profissionais de saúde é adquirida pelo contato com pacientes infectados, colonizados ou a partir de fontes ambientais, usualmente incluindo microrganismos associados a infecções hospitalares ${ }^{10 "}$.

"A flora transitória das mãos é composta pelos microrganismos mais frequentemente responsáveis pelas infecções hospitalares: as bactérias gram-negativas e os estafilococus, o que bem demonstra a importância das mãos como veículo de transmissão ${ }^{3}$ ".

Estudos mostram que a flora transitoria pode tornar-se residente através de adaptação ao meio da pele, se a primeira permanecer em grande número e por um período bastante longo.

"Para se evitar que a flora transitoria se torne residente, é importante que as mãos se jam sempre limpas imediatamente após cada contato com material conta= minado, e, especialmente se o material contiver organismos patogênicos ${ }^{11 "}$.

A análise evolutiva, anteriormente descrita, sobre o controle das infecções hospitalares, nos mostra que a importância dada à lavagem das mãos remota às mais distantes épocas, porém como nos define FUERST ${ }^{11}$ : "... parece que a lavagem das mãos, contudo, é mais ritualista do que realista, embora o papel das mãos na transmissão de infecção não se ja mais discutível".

Convém citar KAWAMOTO ${ }^{15}$ na sua definição da finalidade da lavagem das mãos, por sua clareza e simplicidade: "A lavagem das mãos tem por finalidade evitar a propagação de microrganismos patogênicos, de um indivíduo para outro, através das mãos".

A lavagem das mãos "é considerada o procedimento único mais importante na prevenção das infecções hospitalares, sendo preconizado no controle não só das infiecçōes mais frequentes (urinárias, pneumonias e cirúrgicas), como tamberm nas bacteriemias, gastrenterites, infecções obstétricas, ginecologicas e do trato respiratorio superior ${ }^{10 "}$.

\section{METODOLOGIA}

Estudo exploratorio, com o objetivo de avaliar e incentivar a prática da lavagem das mãos, desenvolvido na Maternidade Escola Assis Chatearbriand, no período de agosto a novembro de 1988.

\section{- Características da População}

A população envolvida no estudo é constituída no seu total, por 82 médicos, 26 enfermeiras e 75 ocupacionais de enfermagem, que prestam assistência direta ao paciente, em áreas consideradas críticas, nos trếs turnos de trabalho.

\section{- Método}

A pesquisa foi desenvolvida nas áreas consideradas críticas assim selecionadas: centro obstétrico, emergência, UTI, sala de recuperação, berçário de infectados, berçário de alto risco e berçário de médio risco.

A escolha da amostra foi determinada pela presença do profissional de saúde ou ocupacional de enfermagem prestando cuidado a clientela, no momento da visita aos referidos setores, tendo um valor amostral de: 24 médicos, 08 enfermeiras e 23 ocupacionais de enfermagem, o que constitui $30 \%$ da população total.

O estudo foi desenvolvido em cinco etapas a saber: A primeira constituiu-se da observação da lavagem das mãos de ocupacionais de enfermagem e profissionais de saúde durante sua rotina laboratorial. A segunda, de coleta de material das mãos para cultura e análise laboratorial. A terceira, da aplicação de um questionário com os participantes da pesquisa microbiologica. A quarta, da análise laboratorial dos sabões encontrados nos setores pesquisados. E, por último, uma proposta de viabilização de estratégias para a divulgação da importância da lavagem das mãos.

\section{- Instrumentos}

Para coletar os dados foram elaborados dois instrumentos: $O$ primeiro para anotações das observações dos profissionais e ocupacionais que caracterizam a amostra; é constituido de 6 questões, sendo 4 fechadas e 2 abertas. $\mathrm{O}$ segundo é um questionário usado pelos participantes da pesquisa microbiologica e é constituido inicialmente, por uma apresentação explicando o motivo da pesquisa, seguindo-se 5 questões, sendo 1 aberta e 4 fechadas, das quais 2 tem opção para complementação das respostas.

\section{- Coleta de Dados}

A coleta foi realizada em quatro momentos:

1. Observação dos profissionais e ocupacionais tendó em vista o anexo I;

2. Coleta de material das mãos para cultura;

3. Aplicação do questionário com os participantes da pesquisa (anexo II);

4. Coleta de amostra dos sabũes encontrados nos setores para ânálise laboratorial.

\section{- Tratamento Estatístico}

Os dados foram apurados manualmente e tabulados com distribuição de frequências absolutas.

\section{DISCUSSÃO DOS RESULTADOS}

Apresentaremos a seguir os resultados obtidos, seguidos de discussão: 
TABELA I - Distribuição da equipe de saúde por categoria de acordo com a "observação" e o "questionário" dos profissionais e ocupacionais de enfermagem sobre a lavagem das mãos - Maternidade Escola Assis Chateaubriand - agosto a novembro de 1988

\begin{tabular}{l|c|c|c|c}
\hline Instrumento & \multicolumn{2}{|c|}{ Observação } & \multicolumn{2}{c}{ Questionário } \\
Lavagem de Māos & & & & \\
Categoria & Sim & Não & Sim & Não \\
\hline Enfermeiro & 06 & 02 & 05 & 03 \\
Médico & 12 & 12 & 20 & 04 \\
Ocupacional & 09 & 14 & 18 & 05 \\
\hline Total & 27 & 28 & 43 & 12 \\
\hline
\end{tabular}

A TABELA II mostra a divergência entre a observação feita pelas pesquisadoras e a resposta do profissional ou ocupacional.

TABELA II - Distribuição da equipe de saúde por categoria de acordo com o motivo que o levou a lavar as mãos antes de prestar cuidados aos pacientes - Maternidade Escola Assis Chateaubriand agosto a novembro de 1988.

\begin{tabular}{l|c|c|c|c}
\hline $\begin{array}{l}\text { Por que Categoria } \\
\text { lavou as mãos? }\end{array}$ & Enfermeiro & Medico & Ocupacional & Total \\
\hline Hábito & - & 01 & 07 & 08 \\
Por Evitar Infecção & 01 & 04 & 02 & 07 \\
cruzada & 04 & 13 & 09 & 26 \\
Ambas & 03 & 04 & 05 & 12 \\
Não Respondeu & - & 02 & - & 02 \\
Outros
\end{tabular}

Analisando estes dados, observamos que a prática da lavagem das mãos é motivada pelo hábito e pela consciência de sua importância concomitantemente.

Gostaríamos de salientar uma resposta dada por um médico que realizava um parto quando o interrogamos sobre os seus motivos para lavar as mãos, na qual ele referiu que as "lavou para merendar" e na análise laboratorial o seu exame continha o maior número de microrganismos.

TABELA III - Distribuição da equipe de saúde por categoria de acordo com o motivo que o levou a não lavar as mãos antes de prestar cuidados aos pacientes - Maternidade Escola Assis Chateaubriand agosto a novembro de 1988 .

\begin{tabular}{|c|c|c|c|c|}
\hline $\begin{array}{l}\text { Por que } \\
\text { não lavou as mãos? }\end{array}$ & Enfermeiro & Médico & Ocupacional & Total \\
\hline Falta de Tempo & - & 02 & 01 & 03 \\
\hline $\begin{array}{l}\text { Não Acha Importante } \\
\text { Falta de Condicoóes }\end{array}$ & - & - & - & 一 \\
\hline Adequadas & - & 02 & - & 02 \\
\hline Não Respondeu & 05 & 20 & 18 & 43 \\
\hline Outros & 03 & - & 04 & 07 \\
\hline
\end{tabular}

Observamos que os motivos mencionados são sempre de ordem exógena, o que para nós não correspondeu à realidade observada, já que em todos os setores existia o material necessário à lavagem das mãos, embora que nem sempre fosse o ideal.

TABELA IV - Distribuição da equipe de saúde por categoria de acordo com o conhecimento das normas do Ministério da Saúde lavagem das mãos - Maternidade Escola Assis Cheteaubriand - agosto a novembro de 1988.

\begin{tabular}{l|c|c|c|c}
\hline \multicolumn{1}{c|}{ Categoria } & Enfermeiro & Medico & Ocupacional & Total \\
\hline Conhecimento & 05 & 15 & 22 & 42 \\
Nim & 03 & 09 & 01 & 13 \\
\hline
\end{tabular}

Estes dados mostram que uma grande maioria dos profissionais e ocupacionais conhecem as normas do Ministério da Saúde, portanto não justifica o descaso com que esta prática é tratada. 
TABELA V - Distribuição da equipe de saúde por categoria de acordo com a contaminação das mãos - Maternidade Escola Assis Chateaubriand - agosto a novembro de 1988.

\begin{tabular}{l|c|c|c|c}
\hline \multicolumn{1}{c|}{ Categoria } & Enfermeiro & Medico & Ocupacional & Total \\
\hline Contaminação & 08 & 21 & 20 & 49 \\
Nim & - & 03 & 03 & 06 \\
\hline
\end{tabular}

Na TABELA $V$ verificamos um alto índice de contaminação, mesmo entre os profissionais e ocupacionais que lavaram as mãos.

Os microrganismos encontrados não podem ser classificados em flora residente ou transitória, porém podemos verificar que de acordo com o estado imunológico do paciente estes podem ser ou não patogênicos.

Vale salientar a expressiva diversificação dos microrganismos encontrados: Stafilococus aureus, grupo assacarolítico, Klebsiela pneumoniae, Pseudomonas maltophila, Pseudomonas aeruginosas, Acinetobacter calcoaceticus, fungo contaminante, Enterobacter, Serratia, Candida albicans, E. coli, Proteus sp, Moraxela sp e Corynebacterium pseudodiphtericus. Este fato representa uma flora hospitalar mais agressiva aos pacientes.

Estes dados levaram à análise laboratorial dos sabões, cu ja contaminação justificou os resultados obtidos.

TABELA VI - Distribuição por setores de contaminação dos sabões - Maternidade Escola Assis Chateaubriand - agosto a novembro de 1988.

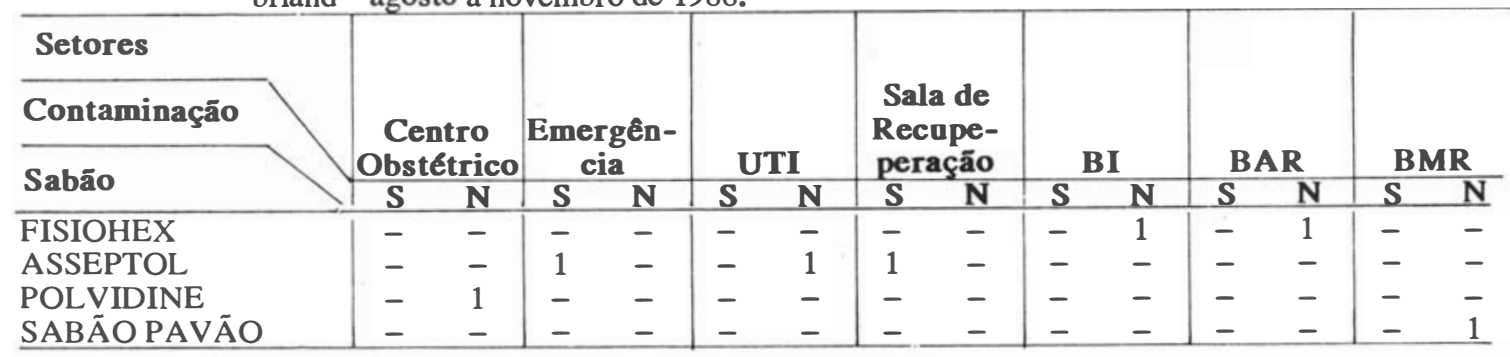

A analise laboratorial mostrou que dentre os sabões, o asseptol estava contaminado. Contaminação esta que não se pode afirmar a sua origem: do proprio

\section{CONCLUSÃO E SUGESTÕES}

Diante dos resultados encontrados, verifica-se que esta prática tem sido pouco valorizada em que torna-se urgente uma maior conscientização da equipe de saúde no sentido de que lavar corretamente as mãos, na sua rotina laborativa, deixa de ser mero hábito para se tornar um meio eficaz de redução dos índices de infecção hospitalar.

Observamos em nossa pesquisa, que a maioria dos componentes da equipe de saúde considerava as mãos lavadas. Acreditamos que este fato se deve a crença de que a lavagem das mãos realizada no momento da chegada ao setor $\varepsilon$ suficiente para a descontaminação das mãos durante todas as atividades.

$\mathrm{O}$ descaso quanto a esta prática deve ser repensado, sob pena de transmitirmos infecções àqueles que recebem nossos cuidados e até mesmo, aos nossos familiares, sem falarmos de uma auto-contaminação.

Podemos ainda afirmar que o desenvolvimento de um técnica correta pode ser facilitada pela presença e localização conveniente de pias nas unidades, bem como a existência do sabão ou anti-séptico adequado.

$\mathrm{O}$ homem, que é a principal vítima das infecções hospitalares, é também o principal veículo transmissor das mesmas, pois dissemina os microrganismos através de suas mãos. Sendo assim, é de fundamental importância que toda a equipe de saúde seja informada e conscientizada da importância da lavagem das mãos no controle das infecções hospitalares. lizadas:

Diante desta realidade, sugerimos que sejam rea- sabão ou do recipiente. . .

A partir destes resultados foi introduzido o uso de escovinhas para a lavagem dos recipientes.

1. Reuniões científicas peri6dicas para discussões sobre lavagem das mãos, com profissionais de nível superior.

2. Treinamento sobre a técnica da lavagem das mãos e a importância de sua prática correta para reduzir os índices de infecções hospitalares.

3. Promoção anual de uma "Semana da Lavagem das Mãos", como instrumento divulgador da importância desta prática no controle das infecções hospitalares.

\section{REFERÊNCIAS BIBLIOGRÁFICAS}

1 BRASIL. Ministério da Saúde. Curso de Introdução ao Controle de Infecção Hospitalar. Secretaria Nacional de Organização e Desenvolvirnento de Serviços de Saúde: Programa de Controle de Infecção Hospitalar, Brasflia, Centro de Documentação do Ministêrio da Saưde.

2 -. Ministério da Saúde. Manual de Controle de Infeç̧ão Hospitalar. Secretaria Nacional de Organização e Desenvolvimento de Serviços de Saúde - Programa de Controle de Infecção Hospitalar, Brasflia, Centro de Documentação do Ministério da Saúde 1985.

3 - Ministério da Saúde. Lavar as Mãos: Informação para Profissionais de Saúde. Secretaria Nacional de Organização e Desenvolvimento de Serviços de Saúde - Programa de Controle de Infecção Hospitalar, Braślia, Centro de Documentação do Ministério da Saúde, 1988. 
4 CASEWELL, M. \& PHILLIPS, I., Hands as route of. transmission for Klebsiela Species, Bsti Med. I., 1977.

5 ESPIRITO SANTO, T.J.M. \& FARIAS, V. Práticas Profilaticas Desenvolvidas por Enfermeiros para evitar Infeç̧ão Cruzada, Rev. Bras. de Enfermagem, Brasflia, jan./mar., ano 88, m. 1, 1985.

6 FERNANDES, A.T., Infecção Hospitalar: Princlpios, Diagnóstico e Profilaxia, Rev. Hospitalar, ano II, no 4, jul./set. 1984.

7 Infecção Hospitalar: Prinćpios, Diagnóstico e Profilaxia Rev. Hospitalar, ano II, m. 4, out./dez. 1984.

8 FERRAZ, E.M., Controle de Infecção Hospitalar. Resultado de um Estudo Prospectivo de Dez Anos em um Hospital Universitário. Tese: UFPE, Recife, 1987.

9 Manual de Controle de Infeç̧ão em Cirurgia, EPU. São Paulo, 1982.

10 FILHO, P.P.G., CARDOSO, C.L. Importância da Lavagem das Mãos no Controle das Infecçōes Hospitalares, In: Rev. Hospitalar, ano II vol II, m. 3, jlu./set. 1984.

11 FUERS T, E.V. et al. Fundamentos de Enfermagem. 5 ed., Interamerioana, Rio de Janeiro: Interamericana, 1977.

12 GRESSLER, L.A., Pesquisa Educacional, 2 ed. São Paulo, Loyola, 1983.

13 HAGUE T TE, T.M.F. Metodologia Qualitativa na Sociologia, Petrópolis: Vozes, 1987.

14 JAWETZ, E., MIELNICK, J.L. Microbiologia Médica, 13 ed. Guanabara Koogan, 1980.
15 KAWAMOTO, E.E., Enfermagem em Clinica Cirnirgica, São Paulo: EPU, 1986.

16 KAWAMOTO, E.E., FOR TES, J.I., Fundamentos de Enfermagem, São Paulo: EPU, 1986.

17 MANDELL, G.L. et al. Principles and Practice of Infections Sideases, Wiley Medical. New York. 1979.

18 MOURA, M.L.P. Sistemas de Controle de Infecção Hospitalar, In: Rev. Hospitalar, ano II, vol II, V, III, m. 4, set.dez. 1984.

19 ROBBINS, S.L. Patologia Estrutural e Funcional, Rio de Janeiro: Interamericana, 1975.

20 SANFORD, J.P. Perspectives in Infection Control, In: WENRL, R.P. Hand Book fo Hospital Acquired Infections, CRC Press, Flórida: Boca Raten, 1981.

21 THORWALD, J. O Século dos Cinurgiōes, São Paulo: Hermous, 1979.

22 YONANS, G.P. et al. The Biological an ClinicalBasic of Infections Diseases, 2 ed. W.B. Philadelphia: Saunders Company, 1980.

23 ZANON, U. Curso sobre Controle de Infecções hospitalares, 7 ed. São Paulo: Centro São Camilo de Desenvolvimento de Administração de Saúde, 1977.

24 ZANON, U., NEVES, J. Infecção Hospitalar - Prevenção, Diagnóstico e Tratamento, Rio de Janeiro: Médica e Cientifica, 1987.

\section{ANEXO I}

\section{INSTRUMENTO DE OBSERVAÇÃO}

1. OCUPAÇÃO

\section{SETOR}

3. Lavou as mãos antes de prestar cuidado ao paciente?
( ) Sim
( ) Não

4. Permitiu que fosse feita a cultura das mãos?
( ) Sim
( ) Não

5. Respondeu o questionário?
( ) Sim
( ) Não

6. Que condições para lavagem das mãos existe no setor?
( ) Pia
( ) Toalha de pano
( ) Toalha de papel
( ) Sabão em barra
( ) Sabão líquido
( ) Saboneteira adequada 


\section{ANEXO II \\ QUESTIONÁRIO}

Prezado colega,

O presente instrumento objetiva uma análise comparativa entre a visão dos profissionais de saúde e a prática da lavagem das mãos.

O preenchimento deste questionário será de grande importância tanto para o diagnóstico da situação atual, quanto para a tomada de medidas de controle de infecção hospitalar.

$\mathrm{Na}$ certeza de sua colaboração, agradecemos antecipadamente.

1. Qual a sua profissão?

2. Você lavou as mãos antes de prestar o cuidado ao paciente que atendeu agora?

( ) $\operatorname{Sim}$ ( ) Não

3. Se sim, por que?

( ) Hábito

( ) Por evitar infecção cruzada

( ) Ambas

( ) Outros

4. Se não, por que?

( ) Falta de tempo

( ) Não acha importante

( ) Falta de condições adequadas? Quais?

5. Você conhece as normas do Ministério da Saúde sobre a lavagem das mãos?

( ) Sim

( ) Não

\section{ASSINE E PARTICIPE DA REBEn}

ENVIANDO TRABALHOS, RESUMOS DE TESES, RESENHAS DE LIVROS, EXPERIENCIAS E SUGESTOES. SUA COLABORAÇĀO É IMPORTANTE! 